\title{
Systematic Localization and Identification of SUMOylation Substrates in Knock-In Mice Expressing Affinity-Tagged SUM01
}

\author{
Marilyn Tirard and Nils Brose
}

\begin{abstract}
Protein SUMOylation is a posttranslational protein modification that is emerging as a key regulatory process in neurobiology. To date, however, SUMOylation in vivo has only been studied cursorily. Knock-in mice expressing $\mathrm{His}_{6}$-HA-SUMOl from the Sumol locus allow for the highly specific localization and identification of endogenous SUMOI substrates under physiological and pathophysiological conditions. By making use of the HA-tag and using wild-type mice for highly stringent negative control samples, SUMOI targets can be specifically localized in and purified from cultured mouse nerve cells and mouse tissues.
\end{abstract}

Key words SUMOylation, Knock-in mice, Affinity purification, Immunoprecipitation, HA-tag, In vivo

1 Introduction

SUMOylation is a reversible, highly dynamic posttranslational protein modification [1]. The consequences of SUMOylation depend on the target protein, and include alterations of protein localization, enzymatic activity, solubility, stability, or interactions [2-4]. In view of this broad functional relevance of SUMOylation, immense efforts have focused over the past two decades on the biochemical enrichment of SUMO targets using anti-SUMO antibodies [5], heterologous expression of tagged SUMOs [6,7], Ubc9 fusiondependent SUMOylation [8], or SUMO-interaction motif domains $[9,10]$. Combined with mass spectrometric identification of candidate proteins, these studies have provided a huge resource of information on SUMO substrates-often including the identification of relevant modified lysine residues-and established protein SUMOylation as a crucial posttranslational protein modification that operates in every eukaryotic cell to regulate its growth, proliferation, differentiation, and function $[7,11-13]$. 
Unfortunately, however, the analysis of endogenous SUMOylation in complex tissues and organisms, such as mouse brain, liver, or heart, has remained challenging. This is a substantial concern, not least because growing evidence indicates an important role of SUMOylation in human diseases that can partly be modeled in genetically modified mice, particularly in neurodegenerative disorders. Consequently, several mutant mouse models have been developed to study SUMOylation in vivo [14-21]. However, most methods described so far focus on enriching SUMOylated protein species for further proteomic analysis, and only few methods are available to combine the specific localization of endogenously SUMOylated protein species with their enrichment. As a consequence, the exact subcellular distribution of endogenous SUMO targets in cells-especially in neurons-is highly debated.

To allow for the precise analysis of the localization of endogenous SUMOI targets and their stringent enrichment, we generated His $_{6}$-HA-SUMOl knock-in (KI) mice that express $\mathrm{His}_{6}$-HASUMO1 from the endogenous Sumol locus, so that overexpression artifacts can be largely excluded [15]. Additionally, these KI mice facilitate the localization and enrichment of SUMOI substrates because anti-HA antibodies usually have higher epitope affinities than anti-SUMOI antibodies and thus provide better signal-to-noise ratios. Further, cells or tissues from wild-type (WT) mice provide highly stringent negative controls when compared to KI material, which boosts the confidence in corresponding results. Finally, the His $_{6}$-HA-SUMOI line can be crossed into any disease model, thus providing the opportunity to study SUMOI conjugation in a plethora of disease-relevant processes. These are clear advantages of the His $_{6}$-HA-SUMOI KI mice over other tools that make them a very useful model system for the analysis of SUMOylation.

Our own research focus is on SUMOylation in neurons for which we used the $\mathrm{His}_{6}$-HA-SUMOI KI model and WT controls. We thus describe step-by-step methods to (1) enrich SUMOI substrates from $\mathrm{His}_{6}$-HA-SUMOl KI mouse brain for subsequent proteomic analysis, based on an anti-HA immunopurification protocol, and to (2) study SUMOI localization in mouse neurons and brain sections. These methods are generally applicable and can be easily adapted to other cell types and tissues. The KI mice can be obtained from us freely, based on an MTA.

\section{Materials}

\subsection{Immuno- precipitation}

Radioimmunoprecipitation assay (RIPA) buffer, $150 \mathrm{mM} \mathrm{NaCl}$, $20 \mathrm{mM}$ Tris-HCl pH $7.4\left(\right.$ at $\left.4{ }^{\circ} \mathrm{C}\right), 1 \%(\mathrm{w} / \mathrm{v})$ Triton X-100, $0.5 \%$ $(\mathrm{w} / \mathrm{v})$ Na-deoxycholate, $0.1 \%(\mathrm{w} / \mathrm{v})$ sodium dodecyl sulfate (SDS). RIPA should be made fresh and cooled at $4{ }^{\circ} \mathrm{C}$. Protease inhibitors (see below) are added shortly before lysis. 
Laemmli SDS-polyacrylamide gel electrophoresis (PAGE) sample buffer, $50 \mathrm{mM}$ Tris $-\mathrm{HCl} \mathrm{pH}$ 6.8, 2\% SDS (w/v), 0.1\% (w/v) bromophenol blue, $10 \%(\mathrm{v} / \mathrm{v})$ glycerol, $10 \mathrm{mM}$ dithiothreitol (DTT, added freshly).

Glycine elution buffer, $0.1 \mathrm{M}$ glycine- $\mathrm{HCl} \mathrm{pH} 2$.

Bead storage buffer, $20 \mathrm{mM}$ Tris- $\mathrm{HCl} \mathrm{pH} 7.5\left(\right.$ at $\left.4{ }^{\circ} \mathrm{C}\right), 100 \mathrm{mM}$ $\mathrm{NaCl}, \quad 0.1 \mathrm{mM}$ ethylenediaminetetraacetic acid (EDTA), $0.09 \%(\mathrm{w} / \mathrm{v}) \mathrm{NaN}_{3}$.

Protease inhibitors: Aprotinin dissolved in water as a $500 \mu \mathrm{g} / \mathrm{ml}$ stock solution and used at a final concentration of $0.5 \mu \mathrm{g} / \mathrm{ml}$, leupeptine dissolved in water as a $1 \mathrm{mg} / \mathrm{ml}$ stock solution and used at a final concentration of $1 \mu \mathrm{g} / \mathrm{ml}$, phenylmethylsulfonyl (PMSF) dissolved in isopropanol as a $17.4 \mathrm{mg} / \mathrm{ml}$ stock solution and used at a final concentration of $17.4 \mu \mathrm{g} / \mathrm{ml}, N$ ethylmaleimide (NEM) dissolved in DMSO as a 1 M stock solution and used at a final concentration of $20 \mathrm{mM}$.

Ultrasonic homogenizer (e.g., Bandelin Sonopuls HD2200, tapered tip KE76).

$100 \%(\mathrm{w} / \mathrm{v})$ methanol.

$100 \%(\mathrm{w} / \mathrm{v})$ chloroform.

HA peptide (custom made).

Chromatography columns ( $10 \mathrm{ml}$ reservoir).

Peristaltic pump.

Anti-HA beads.

$50 \mathrm{ml}$ Falcon tubes.

$1.5 \mathrm{ml}$ Eppendorf tubes.

Porcelain mortar and pestle.

Liquid $\mathrm{N}_{2}$.

Precast gels (e.g., Invitrogen 4-12\% BisTris).

Eppendorf Thermomixer.

Benchtop centrifuge (e.g., Eppendorf 5416, fixed-angle rotor).

Ultracentrifuge (e.g., Beckmann Coulter Optima L-70, rotor $50.2 \mathrm{Ti})$.

Shaker.

2.2 Immunostaining

$1 \times$ PBS, $137 \mathrm{mM} \mathrm{NaCl}, 2.7 \mathrm{mM} \mathrm{KCl}, 10 \mathrm{mM} \mathrm{Na}_{2} \mathrm{HPO}_{4}, 1.8 \mathrm{mM}$ $\mathrm{KH}_{2} \mathrm{PO}_{4}, \mathrm{pH} 7.4$.

Blocking and antibody buffer, $\mathrm{l} \times \mathrm{PBS}, 5 \%(\mathrm{v} / \mathrm{v})$ goat serum, $0.3 \%$ $(\mathrm{w} / \mathrm{v})$ Triton X-100.

Slides (ThermoScientific, SuperFrost Plus).

Mounting medium containing DAPI. 
Cover slips.

Anti-HA antibody.

Secondary goat anti-mouse Alexa-Fluo 555 antibody.

\section{Methods}

\subsection{Immuno- precipitation}

\subsubsection{Preparation of Brain Lysate and Chromatography Column}

3.1.2 Immunoaffinity Binding and Washing of the Column
The following procedure has been optimized for mouse brain but can also be used in order to enrich SUMOylated protein species from other mouse tissues such as heart or liver. Detergent extraction conditions can be altered depending on the tissue and target proteins to be recovered.

1. Kill mice by cervical dislocation.

2. On ice, quickly remove brains from $\mathrm{His}_{6}-\mathrm{HA}-\mathrm{SUMOl} \mathrm{KI}$ and WT mice and remove brainstem.

3. Flash-freeze brains in liquid $\mathrm{N}_{2}$.

4. Grind each brain to fine powder using a precooled porcelain pestle and a precooled porcelain mortar filled with liquid $\mathrm{N}_{2}$.

5. Transfer frozen powder to a $50 \mathrm{ml}$ Falcon tube.

6. Once all liquid $\mathrm{N}_{2}$ has evaporated, add $10 \mathrm{ml}$ of fresh, ice-cold RIPA buffer supplemented with protease inhibitors.

7. Triturate samples by pipetting up and down until complete dissolution of the powder.

8. Sonicate samples on ice for $15 \mathrm{~s}, 8$-pulsed cycles, $75 \%$ of power.

9. Ultracentrifuge samples $\left(100,000 \times \mathfrak{g}, 1 \mathrm{~h}, 4^{\circ} \mathrm{C}\right)$. Carefully remove supernatants for further use.

10. During ultracentrifugation, sediment $0.5 \mathrm{ml}$ of anti-HA beads into a plastic chromatography column and wash with $10 \mathrm{ml}$ of RIPA buffer to equilibrate the beads.

1. Put the supernatant obtained after ultracentrifugation into a $50 \mathrm{ml}$ Falcon tube and add fresh NEM to a final concentration of $20 \mathrm{mM}$. Take a small aliquot and keep on ice for later analysis (Input sample, INP).

2. For efficient depletion of SUMOylated protein species from the lysates, pump samples over the column for $12 \mathrm{~h}$ at a flow rate of $1 \mathrm{ml} / \mathrm{min}$ in the cold room (see Note 1 ).

3. After $12 \mathrm{~h}$, take an aliquot of the lysate and keep on ice for later analysis (flow-through sample, FT).

4. Drain the column of lysate until the meniscus of the lysate almost reaches the column bed (do not let column run dry). Then wash the beads with $40 \mathrm{ml}$ of RIPA containing fresh protease inhibitors and NEM. Once all the washing buffer has passed through the column, start with the elution. 


\subsubsection{Elution}

3.1.4 Precipitation of Proteins from Eluates
1. Take $3 \mathrm{mg}$ of lyophilized HA-peptide from $-20{ }^{\circ} \mathrm{C}$ and let it warm up to room temperature for $30 \mathrm{~min}$.

2. Add $600 \mu \mathrm{l}$ of water to make a stock solution of $5 \mathrm{mg} / \mathrm{ml}$. Mix well until peptides are completely dissolved.

3. Add $5.4 \mathrm{ml}$ of RIPA to make elution buffer at a peptide concentration of $0.5 \mathrm{mg} / \mathrm{ml}$. Keep at room temperature.

4. Carefully resuspend the washed beads in the column with RIPA buffer and transfer them to a fresh $2 \mathrm{ml}$ Eppendorf tube. Pellet the beads by centrifuging gently $(1000 \times g, 3 \mathrm{~min}$, room temperature). Carefully remove with a $1 \mathrm{ml}$ pipet all buffer on top of beads.

5. Add $1.5 \mathrm{ml}$ of elution buffer to each bead aliquot and shake $(1400 \mathrm{rpm})$ in the Thermomixer at $30^{\circ} \mathrm{C}$.

6. Pellet the beads by centrifugation $(1000 \times g, 3 \mathrm{~min}$, room temperature), transfer the first eluate to a fresh tube, and keep on ice.

7. Add another $1.5 \mathrm{ml}$ of elution buffer to the beads and repeat elution as described above. A syringe with a $24 \mathrm{G}$ needle can be used to remove all the eluate without taking beads.

8. Pool both eluates and centrifuge at maximum speed $(23,100 \times g$, $5 \mathrm{~min}$, room temperature) to remove eventual residues of beads. Again, a syringe with a $24 \mathrm{G}$ needle can be used to remove all the eluate without taking beads.

9. From here onwards, eluates can be precipitated and separated on SDS-PAGE (see Subheading 3.1.4) or eluates can be further submitted to Ni-NTA chromatography (see Note 2).

All steps are performed at the bench at room temperature.

1. Prepare $300 \mu \mathrm{l}$ aliquots of pooled eluate in $1.5 \mathrm{ml}$ Eppendorf tubes.

2. Add $400 \mu \mathrm{l}$ of methanol and vortex for $10 \mathrm{~s}$.

3. Add $200 \mu \mathrm{l}$ of chloroform and vortex for $10 \mathrm{~s}$.

4. Add $400 \mu \mathrm{l}$ of distilled water and vortex for $10 \mathrm{~s}$.

5. Centrifuge $(5000 \times g, 3 \mathrm{~min}$, room temperature).

6. Remove upper phase but leave interphase undisturbed as it contains proteins.

7. Add $400 \mu \mathrm{l}$ of methanol and vortex for $10 \mathrm{~s}$.

8. Centrifuge $(23,100 \times g, 5 \mathrm{~min}$, room temperature $)$.

9. Remove supernatant and leave pellet undisturbed.

10. Let the pellet dry at room temperature $(\sim 10 \mathrm{~min})$.

11. Pool all pellets in a final volume of $50 \mu \mathrm{l}$ of Laemmli SDSPAGE sample buffer. 


\subsubsection{Bead Recovery}

\subsubsection{Analysis of Purified} Proteins
1. After elution, resuspend beads in PBS and transfer back to the column.

2. Drain the PBS and add 20 bead volumes of glycine elution buffer.

3. Immediately re-equilibrate the beads with 20 bead volumes of PBS.

4. For storage, drain equilibration buffer and add 20 bead volumes of storage buffer, close the column tightly, and keep at $4{ }^{\circ} \mathrm{C}$.

5. Beads can be reused 3-4 times for Western blot purposes (see Note 3 ).

\section{Western blotting}

The efficiency of the anti-HA affinity purification is determined by Western blotting (Fig. 1). In this example, proteins containing an HA tag were efficiently bound to the matrix as revealed by a reduced anti-HA signal in the flow-through (FT) fraction as compared to the input fraction (INP). Anti-HA substrates were enriched in eluate fractions of the $\mathrm{His}_{6}-\mathrm{HA}$ SUMOl sample (EL KI) but not the WT sample (EL WT). Putative SUMOl-conjugated protein candidates are validated by a Western blotting approach as well. For example, SUMOylated forms of RanGAPl and KAPl were enriched in eluates from KI as compared to WT (Fig. 2).

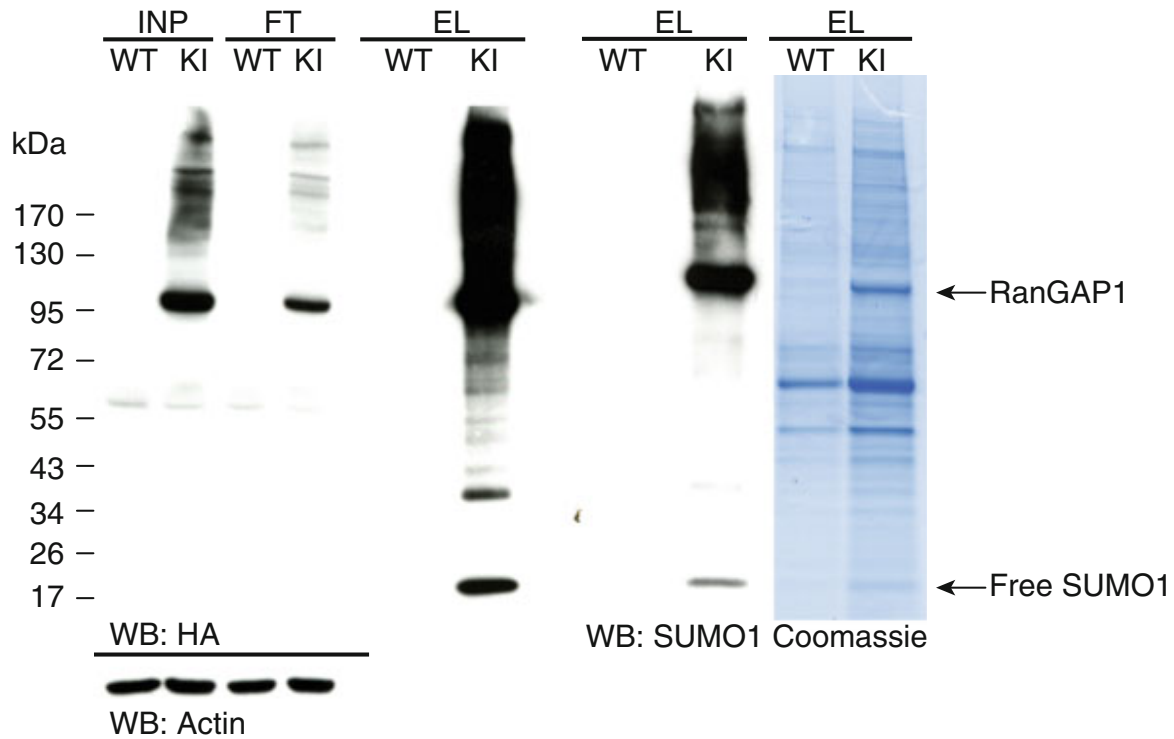

Fig. 1 Anti-HA affinity purification of HA-SUM01 conjugates from P10 wild-type (WT) and $\mathrm{His}_{6}$-HA-SUM01 KI mouse brain (KI). Input (INP), flow-through (FT), and eluate fractions (EL) were analyzed by SDS-PAGE followed by either Coomassie staining (right) or Western blotting (left) using anti-HA and anti-SUM01 antibodies 


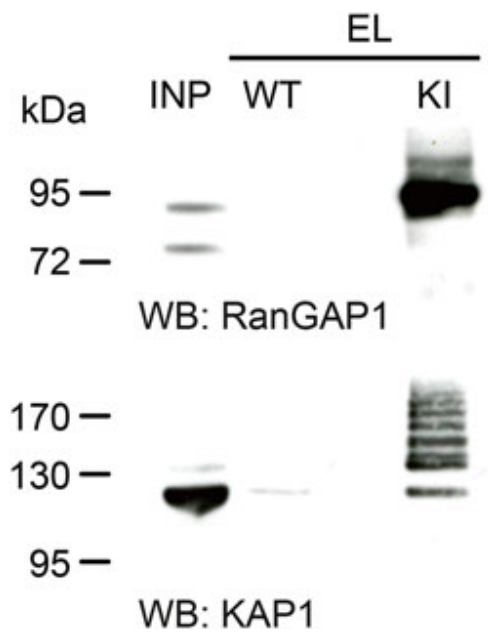

Fig. 2 Western blot analysis of the SUM01 substrates RanGAP1 and KAP1 after anti-HA immunoaffinity purification from WT and $\mathrm{His}_{6}$-HA-SUM01 KI adult mice brain. Input material (from WT) and anti-HA peptide eluates of HA-immunopurified samples from WT and $\mathrm{His}_{6}-\mathrm{HA}$-SUM01 KI were analyzed by Western blot using either anti-RanGAP1 (top) or anti-KAP1 (bottom) antibodies

\section{Mass Spectrometry}

A possible follow-up procedure for proteomic analysis is described elsewhere [22]. Coomassie staining of SDS-PAGE gels loaded with HA peptide eluate fractions from WT mice reveals binding of contaminant proteins to the beads, but increased levels of protein material corresponding to enriched $\mathrm{His}_{6}$-HA-SUMOl targets are seen in eluate fractions from His $_{6}$-HA-SUMOl KI mouse brain (Fig. 1).

\subsection{Immunostaining}

3.2.1 Sample Preparation
As regards the immunostaining of $\mathrm{His}_{6}$-HA-SUMOl-conjugated proteins, we focus on the specific features of the KI mouse model. We only provide a summary of general routine techniques such as perfusion fixation of mice, neuron culture, and fixation of cultured neurons, and refer to the published literature for more details $[23,24]$.

\section{PFA fixation of mouse brain}

$\mathrm{His}_{6}$-HA-SUMOl KI mice and WT littermate are first briefly anesthetized using isoflurane and then deeply anesthetized using Avertin. Mice are transcardiacally perfused with $4 \%$ cold PFA in $0.1 \mathrm{M} \mathrm{PB}$. Brains are then post-fixed for $1 \mathrm{~h}$ in $4 \%$ PFA in $0.1 \mathrm{M}$ $\mathrm{PB}$ at $4{ }^{\circ} \mathrm{C}$ and then placed in $30 \%$ sucrose in $0.1 \mathrm{M} \mathrm{PB}$. Brains are then frozen either on dry ice or directly in the cryostat prior to cutting $30 \mu \mathrm{m}$ thick sections (see Note 4 ). Sections are kept in PBS with $0.09 \%$ azide at $4{ }^{\circ} \mathrm{C}$ until further use.

\section{Primary neuron culture}

Hippocampal or cortical neurons from $\mathrm{His}_{6}$-HA-SUMOl KI and WT littermates are prepared form newborn animals. Brain regions of interest (hippocampi or cortex) are carefully dissected out and digested for $45 \mathrm{~min}$ in a papain solution $(25$ units $/ \mathrm{ml})$ at 
3.2.2 Immuno-labeling HA

3.2.3 Mounting and Imaging $37^{\circ} \mathrm{C}$ with gentle shaking. Papain is then inactivated by incubating the samples in stop solution containing $2.5 \mathrm{mg} / \mathrm{ml}$ bovine serum albumin, $2.5 \%$ (wt/vol) ovalbumin, and $10 \%(\mathrm{vol} / \mathrm{vol})$ fetal bovine serum for $15 \mathrm{~min}$ at $37^{\circ} \mathrm{C}$ with gentle shaking. Hippocampi or cortex pieces are then triturated in neurobasal medium complemented with B27. Neurons are then plated on poly-l-lysine-coated cover slips at a density of 13,000 cells per $\mathrm{cm}^{2}$. After 14 days in vitro, neurons are fixed on ice for $10 \mathrm{~min}$ using $4 \% \mathrm{PFA}$ in PBS with gentle shaking. Cover slips are then washed three times with PBS and kept in PBS at $4{ }^{\circ} \mathrm{C}$ until used.

1. Incubate brain section or cover slip with neurons in $200 \mu \mathrm{l}$ of blocking/permeabilization buffer for $\mathrm{l} h$ at room temperature with gentle shaking ( see Note 5).

2. Remove blocking solution and incubate samples either overnight at $4{ }^{\circ} \mathrm{C}$ (brain sections) or for $2 \mathrm{~h}$ at room temperature (neurons on cover slips) with $200 \mu \mathrm{l}$ blocking/permeabilization solution containing anti-HA primary antibody at a final dilution of $1: 1000$.

3. Carefully remove the primary antibody buffer and slowly add $0.5 \mathrm{ml}$ of PBS. Shake gently for $10 \mathrm{~min}$ at room temperature.

4. Repeat the washing step described above (3) at least three times.

5. Remove washing buffer and incubate samples with $200 \mu \mathrm{l}$ blocking/permeabilization solution containing Alexa-goat anti-mouse 555 at a final dilution of $1: 2000$ for $2 \mathrm{~h}$ (brain sections) or for $\mathrm{l} \mathrm{h}$ (neurons on cover slips) at room temperature with gentle shaking.

6. Carefully remove the buffer with primary antibodies and add $0.5 \mathrm{ml}$ of PBS. Shake gently for $10 \mathrm{~min}$ at room temperature.

7. Repeat the washing step described above (3) at least three times.

\section{Mounting free-floating sections}

(a) Fill up a large glass petri dish with PBS and carefully transfer brain sections into it using a thin brush.

(b) Submerge the glass slide below the brain section.

(c) With a thin brush, mount and flatten the brain section on the slide.

(d) Slowly remove the slide with the brain section from the PBS solution.

(e) Let sample dry for a few minutes by holding the slide vertically.

(f) Add a small drop of mounting medium to the partially dried brain section without touching.

(g) Cover with a cover slip slowly, avoiding air bubble formation. 
(h) Let dry overnight at $4{ }^{\circ} \mathrm{C}$. Imaging can proceed on the next day.

\section{Mounting cover slips}

(a) Place a small drop of mounting medium on a slide.

(b) Carefully and slowly reverse the cover slip of stained neurons onto the drop of mounting medium, avoiding air bubble formation.

(c) Leave overnight at $4{ }^{\circ} \mathrm{C}$ to dry. Imaging can proceed on the next day.

3.2.4 Imaging

Image acquisition is performed as described [15]. Briefly, confocal laser-scanning microscope Leica SP2 or SP5 was used to acquire serial confocal images. Settings (gain and offset) were kept constant for a given staining and genotypes to allow for fluorescence intensity comparison. High-resolution analysis of anti-HA labeling of $\mathrm{His}_{6}-\mathrm{HA}$ SUMOI brain sagittal sections (Fig. 3) or cultured neurons (Fig. 4) revealed a strong nuclear and nuclear envelope labeling of cells as compared to WT. Line scanning through cell bodies and dendrites of triple-labeled CA3 hippocampal neurons using anti-HA, anti-MAP2, and anti-Synapsin 1 antibodies showed that extra nuclear $\mathrm{His}_{6}-\mathrm{HA}$ SUMOl conjugates are not localized at synapses (Fig. 3, white arrow), an observation that was further confirmed by double immunostaining of primary hippocampal neurons using anti-HA and anti-Synapsin 1 (Fig. 4, white arrow).
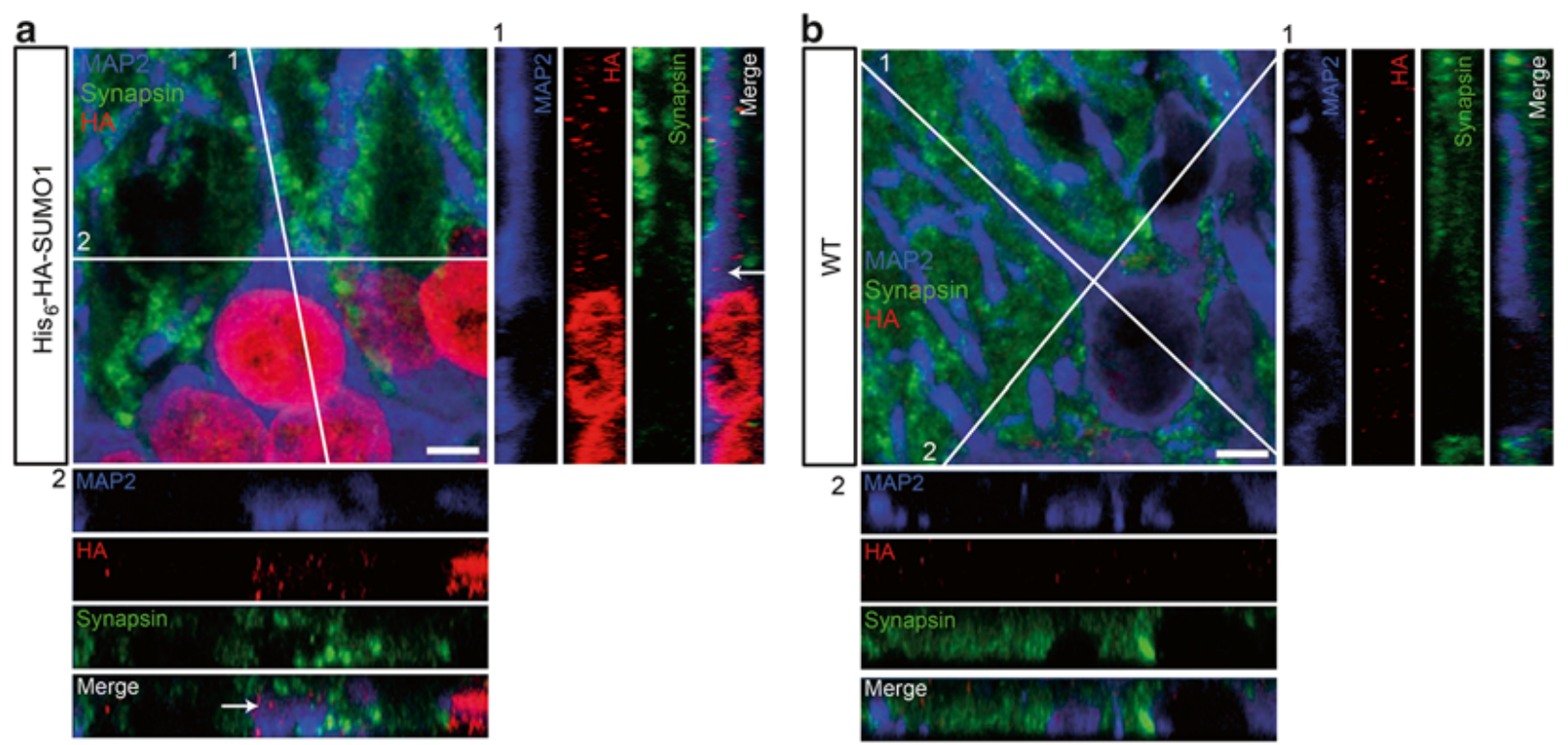

Fig. 3 Localization of $\mathrm{His}_{6}$-HA-SUM01 conjugates in the cytosol and the nucleus of CA3 hippocampal neurons of $\mathrm{His}_{6}-\mathrm{HA}$-SUM01 mice. Sagittal brain sections from KI (a) and WT (b) mice were stained using antibodies to HA (red), Synapsin 1 (green; presynaptic terminals), and MAP2 (blue; neuronal dendrites). The white line shows the orientation of the scan used to generate the image stacks shown in side view on the right and bottom. Scale bar, $10 \mu \mathrm{m}$. The white arrows indicate that extra nuclear $\mathrm{His}_{6}-\mathrm{HA}-\mathrm{SUM} 01$ conjugates are not localized at synapses 


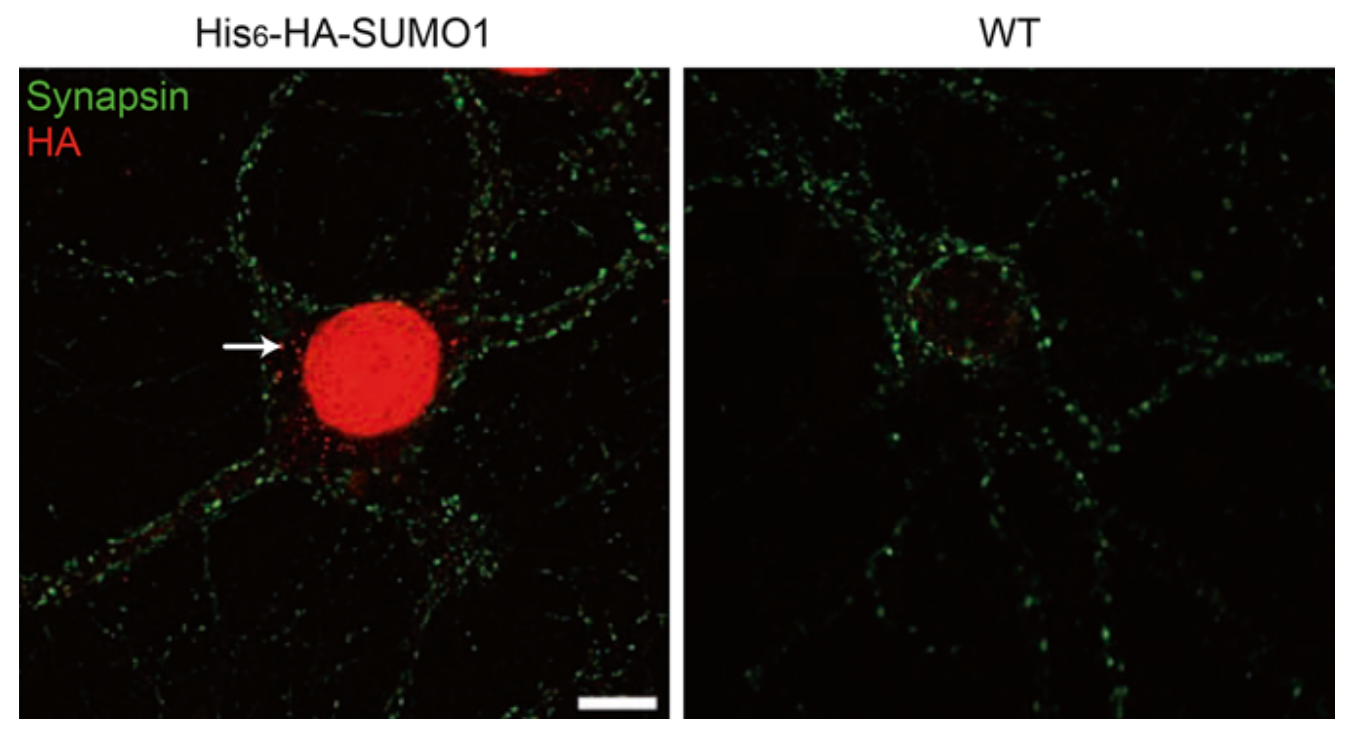

Fig. 4 Localization of $\mathrm{His}_{6}$-HA-SUM01 conjugates in the cytosol and nucleus of $\mathrm{His}_{6}-\mathrm{HA}-\mathrm{SUMO1} \mathrm{KI}$ neurons. Images of KI (left) and WT control (right panel) primary hippocampal neurons are shown. Neurons were stained using antibodies to HA ( $r e d$ ) and Synapsin 1 (green; presynaptic terminals). Scale bar, $10 \mu \mathrm{m}$. The white arrow indicates that extra nuclear $\mathrm{His}_{6}-\mathrm{HA}$-SUM01 conjugates are not localized at synapses

\section{Notes}

1. For higher enrichment of $\mathrm{His}_{6}$-HA-SUMOl targets, it is recommended to use a chromatography-based procedure instead of a batch adsorption protocol.

2. A two-step purification (nickel-nitrilotriacetic acid (Ni-NTA) combined with anti-HA affinity purification) successfully enriches His $_{6}$-HA-SUMOl substrates for Western blot analysis as compared to WT but does not yield enough material for routine proteomics analysis, independently of whether the Ni-NTA chromatography is performed before or after anti-HA affinity chromatography. The reason for this is the loss of proteins when changing between biological and denaturing buffers. Additionally, single Ni-NTA chromatography to enrich $\mathrm{His}_{6}$-HA-SUMOl substrates from $\mathrm{His}_{6}-\mathrm{HA}-\mathrm{SUMOl} \mathrm{KI}$ and WT leads to major nonspecific binding [16]. Therefore, we recommend performing the Ni-NTA chromatography as a second purification step. A detailed description of our Ni-NTA chromatography protocol from mouse brain is described elsewhere [25].

3. When a mass spectrometric comparative analysis of WT and His $_{6}$-HA-SUMOl KI material is planned, a fresh batch of beads should be used.

4. Isopentane freezing of mouse brains did not result in proper staining of RanGAPl at the nuclear pore complex.

5. We do not recommend using digitonine for the permeabilization of neurons, as in our hands it does not prevent the strong labeling of the nuclear envelope and leads to poor labeling of neuronal synapses with antibodies to synaptic markers. 


\section{References}

1. Flotho A, Melchior F (2013) Sumoylation: a regulatory protein modification in health and disease. Annu Rev Biochem 82:357-385

2. Psakhye I, Jentsch S (2012) Protein group modification and synergy in the SUMO pathway as exemplified in DNA repair. Cell 151:807-820

3. Jentsch S, Psakhye I (2013) Control of nuclear activities by substrate-selective and proteingroup SUMOylation. Annu Rev Genet 47:167-186

4. Gareau JR, Lima CD (2010) The SUMO pathway: emerging mechanisms that shape specificity, conjugation and recognition. Nat Rev Mol Cell Biol 11:861-871

5. Barysch SV, Dittner C, Flotho A, Becker J, Melchior F (2014) Identification and analysis of endogenous SUMOI and SUMO2/3 targets in mammalian cells and tissues using monoclonal antibodies. Nat Protoc 9:896-909

6. Pichler A (2008) Analysis of sumoylation. Methods Mol Biol 446:131-138

7. Hendriks IA, D'Souza RC, Chang JG, Mann M, Vertegaal AC (2015) System-wide identification of wild-type SUMO-2 conjugation sites. Nat Commun 6:7289

8. Niedenthal R (2009) Enhanced detection of in vivo SUMO conjugation by Ubc9 fusiondependent sumoylation (UFDS). Methods Mol Biol 497:63-79

9. Lang V, Aillet F, Da Silva-Ferrada E, Xolalpa W, Zabaleta L, Rivas C, Rodriguez MS (2015) Analysis of PTEN ubiquitylation and SUMOylation using molecular traps. Methods 77-78:112-118

10. Da Silva-Ferrada E, Xolalpa W, Lang V, Aillet F, Martin-Ruiz I, de la Cruz-Herrera CF, Lopitz-Otsoa F, Carracedo A, Goldenberg SJ, Rivas C, England P, Rodriguez MS (2013) Analysis of SUMOylated proteins using SUMO-traps. Sci Rep 3:1690

11. Rosas-Acosta G, Russell WK, Deyrieux A, Russell DH, Wilson VG (2005) A universal strategy for proteomic studies of SUMO and other ubiquitin-like modifiers. Mol Cell Proteomics 4:56-72

12. Tatham MH, Matic I, Mann M, Hay RT (2011) Comparative proteomic analysis identifies a role for SUMO in protein quality control. Sci Signal 4:rs4. doi: 10.1126/scisignal.2001484

13. Matic I, van Hagen M, Schimmel J, Macek B, Ogg SC, Tatham MH, Hay RT, Lamond AI, Mann M, Vertegaal AC (2008) In vivo identification of human small ubiquitin-like modifier polymerization sites by high accuracy mass spectrometry and an in vitro to in vivo strategy. Mol Cell Proteomics 7:132-144
14. Matsuzaki S, Lee L, Knock E, Srikumar T, Sakurai M, Hazrati LN, Katayama T, Staniszewski A, Raught B, Arancio O, Fraser PE (2015) SUMOl affects synaptic function, spine density and memory. Sci Rep 5:10730

15. Tirard M, Hsiao HH, Nikolov M, Urlaub $H$, Melchior F, Brose N (2012) In vivo localization and identification of SUMOylated proteins in the brain of His6-HA-SUMOl knock-in mice. Proc Natl Acad Sci U S A 109:21122-21127

16. Rossner MJ, Tirard M (2014) Thyl.2 driven expression of transgenic His(6)-SUMO2 in the brain of mice alters a restricted set of genes. Brain Res 1575:1-11

17. Yang W, Sheng H, Thompson JW, Zhao S, Wang L, Miao P, Liu X, Moseley MA, Paschen W (2014) Small ubiquitin-like modifier 3 -modified proteome regulated by brain ischemia in novel small ubiquitin-like modifier transgenic mice: putative protective proteins/ pathways. Stroke 45:1115

18. Wang L, Rodriguiz RM, Wetsel WC, Sheng H, Zhao S, Liu X, Paschen W, Yang W (2014) Neuron-specific Sumol-3 knockdown in mice impairs episodic and fear memories. J Psychiatry Neurosci 39:259-266

19. Lee YJ, Mou Y, Maric D, Klimanis D, Auh S, Hallenbeck JM (2011) Elevated global SUMOylation in Ubc9 transgenic mice protects their brains against focal cerebral ischemic damage. PLoS One 6:e25852. doi: 10.1371/ journal.pone.0025852

20. Zhang FP, Mikkonen L, Toppari J, Palvimo JJ, Thesleff I, Janne OA (2008) Sumo-I function is dispensable in normal mouse development. Mol Cell Biol 28:5381-5390

21. Wang L, Wansleeben C, Zhao S, Miao P, Paschen W, Yang W (2014) SUMO2 is essential while SUMO3 is dispensable for mouse embryonic development. EMBO Rep 15:878-885

22. Hsiao HH, Meulmeester E, Urlaub H (2012) Identification of endogenous SUMOI accepter sites by mass spectrometry. Methods Mol Biol 893:431-441

23. Peng Y, Xiong WC, Mei L (2013) Culture of dissociated hippocampal neurons. Methods Mol Biol 1018:39-47

24. Gage GJ, Kipke DR, Shain W (2012) Whole animal perfusion fixation for rodents. J Vis Exp (65). doi: $10.3791 / 3564$

25. Krumova P, Meulmeester E, Garrido M, Tirard M, Hsiao HH, Bossis $G$, Urlaub $H$, Zweckstetter M, Kugler S, Melchior F, Bahr M, Weishaupt JH (2011) Sumoylation inhibits alpha-synuclein aggregation and toxicity. J Cell Biol 194:49-60 